\title{
Infratentorial Oligodendroglioma in a Child: A Case Report and Review of the Literature
}

\author{
Bir Clocukta Infratentorial Oligodendrogliom: Bir Olgu Sunumu ve \\ Literatürün Gözden Geçrilmesi
}

\author{
Fatma El OUNI ${ }^{1}$, Mehdi GAHA ${ }^{1}$, Hassen MOULAHI ${ }^{1}$, Abderrahmen DAADOUCHA ${ }^{1}$, Hedi KRIFA ${ }^{2}$, \\ Kalthoum TLILI ${ }^{1}$ \\ ${ }^{1}$ Sabloul University Hospital, Department of Radiology, Sousse, Tunisia \\ ${ }^{2}$ Sabloul University Hospital, Department of Neurosurgery, Sousse, Tunisia
}

Correspondence address: Fatma El OUNI / E-mail: elounichedia@yahoo.fr

\begin{abstract}
Oligodendrogliomas are the tumors of normal glial cells of brain called oligodendrocytes. They represent a small proportion of childhood brain tumors and are infrequently encountered in the posterior fossa. CT scan and MRI are very helpful for the preoperative management of oligodendrogliomas. However, due to the rarity and non-specific imaging features, it may be difficult to differentiate oligodendroglioma from astrocytoma especially in an infratentorial location. The short- and long-term outcome and the exact treatment protocol of posterior fossa oligodendroglioma is yet to be established. We report a rare case of an oligodendroglioma of the vermis in an 8-year-old female with a brief review of the literature.
\end{abstract}

KEYWORDS: Oligodendroglioma, Infratentorial, Child, MRI

\section{öz}

Oligodendrogliomlar beynin oligodendrosit adı verilen normal glial hücrelerinin tümörleridir. Çocukluk çağı beyin tümörlerinin küçük bir kısmını oluştururlar ve posterior fossada bulunmaları nadirdir. BT tarama ve MRG oligodendrogliomların preoperatif takibi için çok faydalıdır. Ancak nadirliği ve spesifik olmayan görüntüleme özellikleri nedeniyle özellikle infratentoriyal konumda oligodendrogliomu astrositomdan ayırt etmek zor olabilir. Posterior fossa oligodendrogliomunun kısa ve uzun dönemli sonucu ve kesin tedavi protokolü henüz belirlenmemiştir. Sekiz yaşındaki bir kız çocukta nadir bir vermis oligodendrogliomu vakası sunuyor ve literatürü kısaca gözden geçiriyoruz.

ANAHTAR SÖZCÜKLER: Oligodendrogliom, İnfratentorial, Çocuk, MRG

\section{INTRODUCTION}

Oligodendrogliomas are tumors of normal glial cells of the brain called oligodendrocytes. They represent approximately $4 \%$ of all primary brain tumors and less than $1 \%$ of primary childhood brain tumors (3). The initial diagnosis has two incidence peaks: $6-12$ years and $35-44$ years. Only about $7.5 \%$ of cases are diagnosed in children. Oligodendrogliomas are supratentorial tumors in more than $90 \%$ of cases (7). We report an infratentorial oligodendroglioma in an 8-year-old girl with a brief review of the literature.

\section{CASE REPORT}

An 8-year-old female presented with vertigo, nausea, vomiting and headache of two weeks duration. She was also suffering from mental status changes (according to her parents) and visual complaints, but she experienced no seizure. On examination, she had gait ataxia, cerebellar syndrome, left sixth nerve palsy and papilledema. CT scan showed a midline mixed density lesion of the posterior fossa extending to left cerebellar hemisphere with areas of calcification (Figure 1A) and ring enhancement on contrast administration (Figure 1B). On MRI, the tumor was hypointense on T1-weighted images (Figure 2A), hyperintense on T2-weighted images (Figure 2B) with a peripheral enhancement after gadolinium administration (Figure 2C). This tumour was responsible for fourth ventricle compression and hydrocephalus. Tumor excision was performed and histopathological analysis revealed a low-grade oligodendroglioma, consisting of small round cells with nuclei, surrounded by a halo, demonstrating a characteristic "fried egg" appearance (Figure 3). No metastasis outside the central nervous system was found. Local and prophylactic craniospinal radiotherapy was performed. There was no technical capacity to look for $1 p$ and $19 q$ deletions.

The MRI showed no local tumoral recurrence three months later. No delayed cerebrospinal fluid metastases occurred.

\section{DISCUSSION}

Oligodendrogliomas are malignant tumors of glial cells. They represent the third most common type of gliomas (4 to $15 \%$ of gliomas) and 2 to $5 \%$ of primary brain tumors (5, 

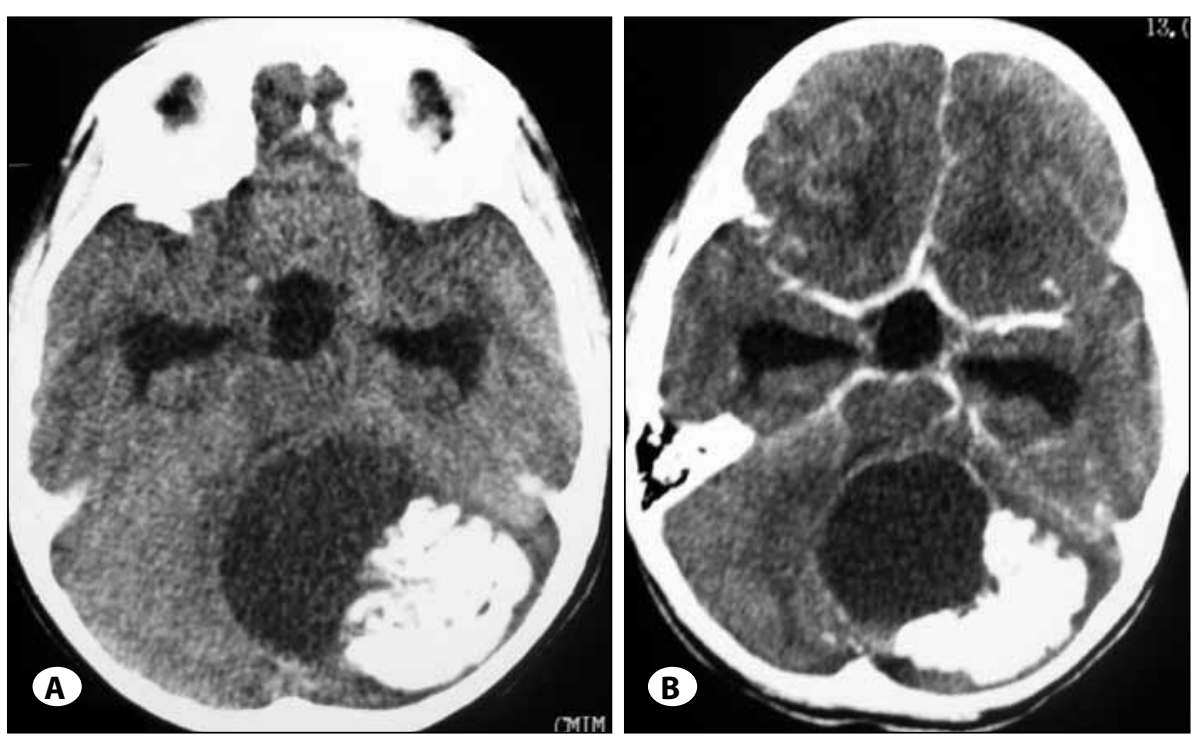

Figure 1: Axial CT-scan of the brain showing a hypodense mass lesion in the vermis and left cerebellar hemisphere with areas of calcification (A) and peripheral enhancement on contrast administration (B).
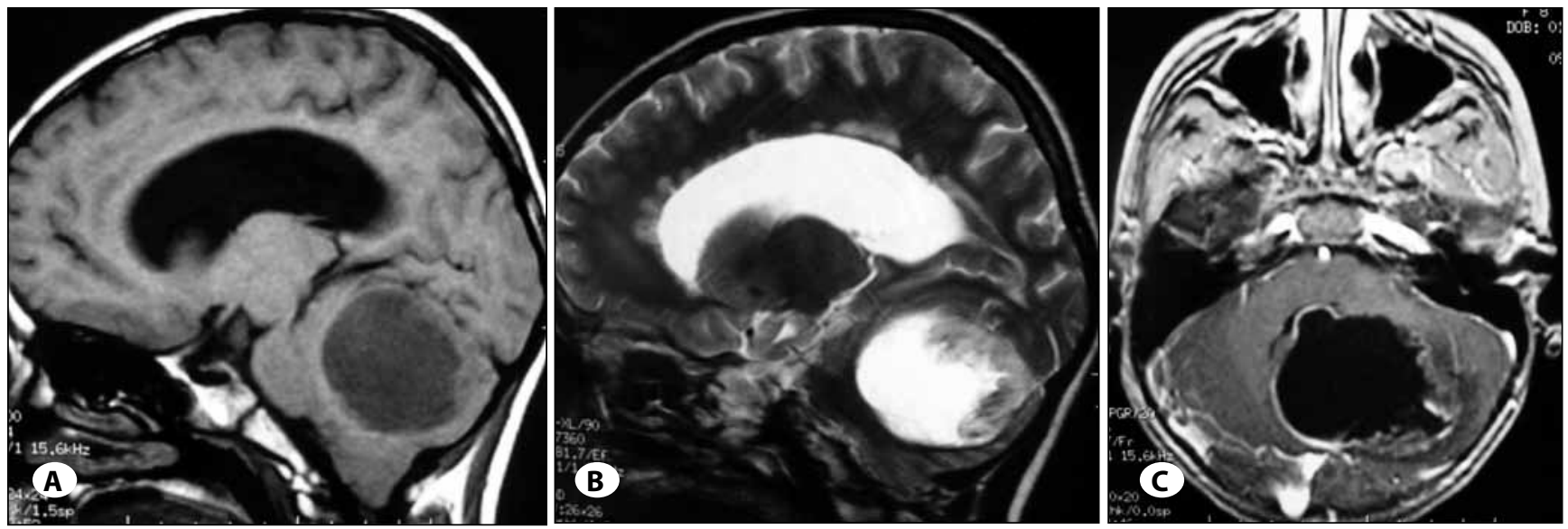

Figure 2: MRI of the brain showing sharply defined cystic lesion of vermis, extending to the left cerebellar hemisphere and responsible for fourth ventricle compression, that is hypointense on the T1-weighted image (A), hyperintense on the T2-weighted image (B), with ring enhancement after gadolinium administration on the T1-weighted enhanced image (C).

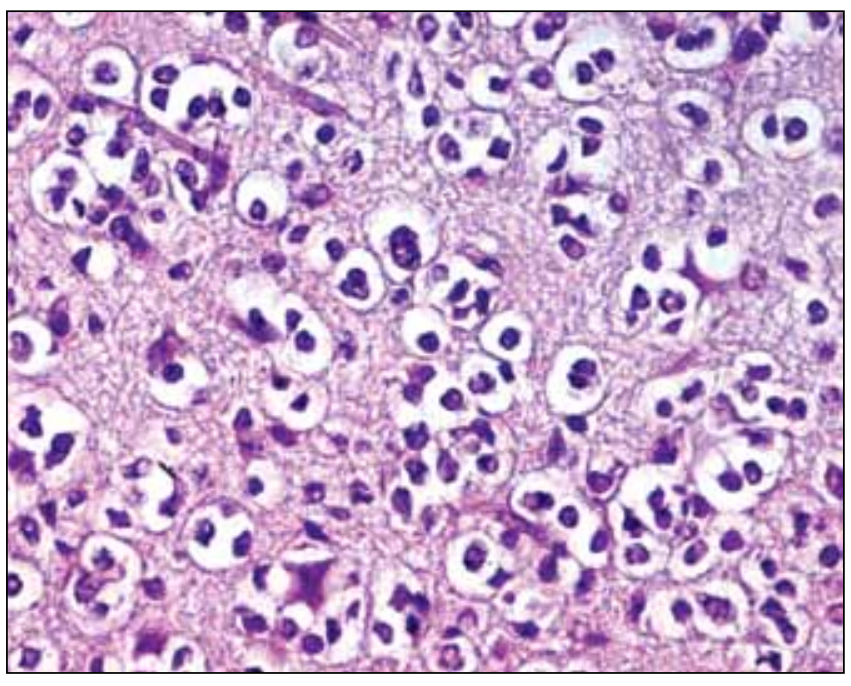

Figure 3: Photomicrograph showing small round cells with nuclei, surrounded by a halo, demonstrating a characteristic "fried egg" appearance (hematoxylin and eosin staining, 400x).
13). Oligodendrogliomas may occur at any age, but the initial diagnosis has two incidence peaks: 6-12 years and 35-44 years (14). Only about $7.5 \%$ of cases are diagnosed in children, representing a small proportion (about 1\%) of childhood brain tumors $(5,12)$. The tumor is somewhat more common in males, with sex-ratio ranging from 1.1 to 2.0 (5).

Oligodendroglial tumors may occur anywhere oligodendrocytes are present. Like astrocytomas, their distribution is usually proportional to the normal distribution of their cell type within the central nervous system (CNS) $(4,5)$. More than $90 \%$ arise in the supratentorial white matter, most commonly in the frontal and temporal lobes (5). Less than $10 \%$ occur in the posterior fossa and spinal cord $(5,7,10)$.

Oligodendroglial tumors have a tendency to invade the leptomeninges $(4,13)$. Delayed cerebrospinal fluid metastases (either leptomeningeal seeding or "drop metastases") occur in 1 to $2 \%$ of cases (5). Oligodendrogliomas seem to be more likely to metastasize outside the CNS (to bone, 
lung, pleura, and liver) than other gliomas (5). Infratentorial oligodendrogliomas may be more malignant than supratentorial ones (7). Oligodendroglioma of the posterior cranial fossa occurring in early infancy or adolescence is characterized by clinical aggressiveness and frequent metastases to the leptomeninges (11).

The symptoms of oligodendroglial tumors do not reliably distinguish them from other types. In most series, seizure has been the most common presenting symptom, ranging in incidence from $35 \%$ to $85 \%$ of patients (5). Seizures from oligodendrogliomas may be generalized, simple partial, complex partial, or a combination. Other presenting symptoms have included headaches, mental status changes, vertigo, nausea, visual complaints, and/or localized weakness (1, 5). Classically, it has been observed that patients with oligodendrogliomas often experience symptoms (usually seizures) for a number of years prior to their diagnosis, which was definitively made after an apoplectic event such as a peritumoral haemorrhage. The clinical course of oligodendroglioma in the posterior cranial fossa is relatively indolent and symptoms are usually long-standing (9). Packer et al reported a child with posterior fossa oligodendroglioma who had insertion of ventriculoperitoneal shunt for hydrocephalus 10 years prior to the diagnosis of the tumor (11).

Imaging findings of oligodendrogliomas may be characteristic but are not pathognomonic (5). Specific immunohistochemical staining methods and electron microscopy help in the differential diagnosis but are not mandatory for the diagnosis (15).

Usually, these tumors are found in the cortex and/or subcortical white matter with fairly discrete margins (49\% to 59\%) and variable contrast enhancement (5). Peritumoral oedema and mass effect are usually minimal or absent, despite the size of the tumor. Oligodendroglioma is the intracranial tumor that develops calcifications most often, up to $90 \%$ in some series $(5,6)$. Calcifications often present a coarse appearance, and punctate or linear calcifications may also occur. Since astrocytomas may also calcify and are more common, a glial tumor with calcium deposits is more likely to be an astrocytoma than an oligodendroglioma (6). Due to their location and slow-growing nature, oligodendrogliomas may cause calvarial erosion (5). Like all brain tumors, MRI has dramatically improved the management of oligodendroglioma; CT scan is interesting only for calcification detection and bone analysis. On MRI, an oligodendroglioma is typically hypointense on T1-weighted images and hyperintense on T2-weighted images, often appearing fairly well demarcated and with little peritumoral edema $(5,6)$. Since intratumoral haemorrhage, areas of cystic degeneration, and/or calcifications may all be present, oligodendrogliomas may demonstrate a heterogeneous appearance (6). Tumor enhancement is of a great prognostic value because it is highly predictive of high-grade oligodendroglioma. Enhancement may be either patchy or homogeneous. When ring enhancement is present (which is rare), it has been reported to herald a poor prognosis. With contrast enhancement as a variable, a grading classification for oligodendrogliomas was suggested and was found to be highly predictive of survival. Like other glial tumors, oligodendrogliomas may spread through the corpus callosum and along the leptomeninges or ependyma $(5,13)$. Although infratentorial oligodendrogliomas do not show characteristic imaging findings, there is a tendency toward multifocal heterogeneous enhancement and absent or mild mass effect of infiltrative lesions (6). Calcifications, enhancement, and edema are seen less frequently in children and adolescents with oligodendrogliomas than in adults (5).

Oligodendrogliomas are treated with surgical extirpation followed by local radiation therapy. Packer et al reported four children with a median age of 7.5 years who harbored histologically malignant oligodendrogliomas of the cerebellum (11). Three patients received local radiation therapy and all had recurrent disease at a median of 11 months. The relapse in each case was outside the radiation field, with stable disease at the primary site. One child treated with craniospinal irradiation was disease free 15 months after treatment. Because of the tendency to metastasize via the cerebrospinal fluid, some authors recommended cerebrospinal fluid cytology in all cases to determine the need for spinal axis irradiation. Others suggested that the oligodendroglioma of the posterior fossa should be considered potentially malignant and treated with local as well as prophylactic craniospinal radiotherapy (9). Current treatment modalities for low-grade gliomas include surgery, radiotherapy and chemotherapy. Cases of oligodendroglioma occurring in paediatric patients demonstrate resistance to chemotherapy (2). Management of these ultimately incurable tumors remains controversial, particularly the timing and extent of surgery, and the optimal sequence of radiotherapy and chemotherapy thereafter $(8,15)$.

In recent years, significant advances have been made in the treatment of oligodendrogliomas, based primarily on molecular subtyping of lesions. Deletions resulting in loss of heterozygosity of the $1 p$ and $19 q$ segments of intratumoral chromosomes have correlated closely with a favorable response to chemotherapy (15).

The short and long-term outcome and the exact treatment protocol of posterior fossa oligodendroglioma are yet to be established due to the paucity of cases. The prognosis appears to be good if the tumor is resected early, the histology does not show malignancy and after treatment with craniospinal irradiation $(8,15)$.

\section{REFERENCES}

1. Allam A, Radwi A, El Weshi A, Hassounah M: Oligodendroglioma: An analysis of prognostic factors and treatment results. Am J Clin Oncol 23:170-175, 2000

2. Chen R, Macdonald DR, Ramsay DA: Primary diffuse leptomeningeal oligodendroglioma. Case report. J Neurosurg 83: 724-728, 1995

3. Chitkara N, Chanda R, Thakur AK, Chanda S, Sharma NK: Posterior fossa oligodendroglioma. Indian J Pediatr 69(12): 1099-1100, 2002 
4. Engelhard $\mathrm{HH}$, Stelea A, Cochran EJ: Oligodendroglioma: Pathology and molecular biology. Surg Neurol 57:111-117, 2002

5. Engelhard $\mathrm{HH}$, Stelea A, Mundt A: Oligodendroglioma and anaplastic oligodendroglioma: Clinical features, treatment, and prognosis. Surg Neurol 60(5):443-456, 2003

6. Lee $C$, Duncan WV, Young AB: Magnetic resonance features of the enigmatic oligodendroglioma. Investigative Radiol 33: 222-231, 1998

7. Lee $\mathbf{H}$, Kim ST, Suh $Y L$, Kim HJ, Kim KH, Jeon P, Byun HS: Infratentorial oligodendrogliomas: Imaging findings in six patients. Acta Radiol 51(2):213-217, 2010

8. Lwin Z, Gan HK, Mason WP: Low-grade oligodendroglioma: Current treatments and future hopes. Expert Rev Anticancer Ther 9(11):1651-1661, 2009

9. Nadkarni TD, Menon RK, Desai Kl, Goel AH: Cerebellar oligodendroglioma in a young adult. J Clin Neurosci 12(7):837-838, 2005
10. Olson JD, Riedel E, DeAngelis LM: Long-term outcome of low-grade oligodendroglioma and mixed glioma. Neurology 54:1442-1448, 2000

11. Packer RJ, Sutton LN, Rorke LB, Zimmerman RA, Littman $P$, Bruce DA, Schut L: Oligodendroglioma of the posterior fossa in childhood. Cancer 56:195-199, 1985

12. Razack N, Baumgartner J, Bruner J: Pediatric oligodendrogliomas. Pediatr Neurosurg 28:121-129, 1998

13. Reifenberger G, Kros JM, Burger PC, Louis DN, Collins VP: Oligodendroglioma. In: Kleihues P, Cavenee WK, (eds), Tumours of the Nervous System. Pathology and Genetics. Lyon: IARC Press, 2000:56-61

14. Wrensch MR, Minn Y, Bondy ML. Epidemiology: In: Bernstein M, Berger M, (eds), Neuro-Oncology: The Essentials. New York: Thieme, 2000:2-17

15. Zada G, McNatt SA, Gonzalez-Gomez I, McComb JG: Anaplastic intraventricular oligodendroglioma: Case report and review of the literature. Surg Neurol 71(6):693-700, 2009 